\title{
UTILIZAÇÃO DE BIOMASSA EM AULAS DE GRADUAÇÃO DE QUÍMICA ORGÂNICA EXPERIMENTAL: EXTRAÇÃ̃O DE FLAVONOIDES A PARTIR DE RESÍDUOS DE CASCAS DE FRUTAS CÍTRICAS
}

\author{
Mauricio M. Victor ${ }^{\mathrm{a}, \mathrm{b}, \mathrm{c}, *,([)}$, Juliana L. Leite ${ }^{\mathrm{a}, \mathrm{b}}$, Gabriel S. Ramos ${ }^{\mathrm{a}, \mathrm{b}}$, Jorge M. David ${ }^{\mathrm{a}, \mathrm{c}}$ e Klauber V. Cardoso ${ }^{\mathrm{a}}$ \\ ${ }^{a}$ Departamento de Química Orgânica, Instituto de Química, Universidade Federal da Bahia, 40170-115 Salvador - BA, Brasil \\ ${ }^{b}$ Centro Interdisciplinar em Energia e Ambiente, Universidade Federal da Bahia, 40170-115 Salvador - BA, Brasil \\ 'Instituto Nacional de Ciência e Tecnologia em Energia e Ambiente, Universidade Federal da Bahia, 40170-115 Salvador - BA, Brasil
}

Recebido em 09/04/2020; aceito em 29/06/2020; publicado na web em 07/08/2020

\begin{abstract}
EMPLOYMENT OF BIOMASS IN UNDERGRADUATE ORGANIC CHEMISTRY EXPERIMENTAL CLASSES: EXTRACTION OF FLAVONOIDS FROM CITRUS FRUIT PEEL WASTE. This work describes the importance of using renewable sources in experimental classes for undergraduate students, as well as to spread the ideas of using biomass wastes as a source of products of interest. Therefore, in the proposed experiment, citrus fruit peel waste was employed to obtain pure flavonoids by extraction and recristalization. These procedures are important to reveal to students how bioactive products can be easily obtained from natural sources. In this way, naringin and hesperidin could be efficiently extracted from grapefruit (Citrus x. paradisi L.) and common orange (Citrus sinensis L. osbeck) peel wastes, respectively, using simple alcohols as solvents.
\end{abstract}

Keywords: citrus peel waste; naringin extraction; hesperidin extraction; flavonoids; undergraduate experiment.

\section{INTRODUÇÃO}

A realização de experimentos de química orgânica pelos estudantes, em seus cursos de graduação, é um excelente momento no qual os professores podem inserir em sua aprendizagem conceitos mais atuais e ambientalmente sustentáveis. A questão do uso de biomassa como fonte de produtos químicos de interesse tem sido negligenciada nas aulas experimentais dos cursos de graduação. Propostas de atividades laboratoriais sem aplicação prática pode ser desmotivador para os discentes de diferentes cursos de graduação que possuem aulas experimentais de Química Orgânica. Isso por que em muitos experimentos práticos não fica clara a real aplicação dos princípios modernos da química, transmitindo assim, aos discentes, uma mensagem de pouca importância da valorização dos insumos, produtos e rejeitos, e de uma química e ciência cada vez mais sustentáveis e ambientalmente corretas.

Nesse contexto, o surgimento dos princípios da Química Verde contribuiu para uma mudança dos rumos da ciência e da pesquisa, retirando o foco da exploração desenfreada de recursos naturais não renováveis e transferindo-o para o conceito do desenvolvimento sustentável. ${ }^{1}$ Essa transformação autocrítica e reflexiva que a ciência química tem passado é parte de um movimento mais abrangente e complexo, onde a preocupação com os questões ambientais, oriundas dos processos tradicionais, levou a uma alteração na percepção e no modus operandi de se fazer ciência e pesquisa, seja no âmbito industrial ou no acadêmico. Essa nova compreensão da Química Verde foi sintetizada nos bem conhecidos "12 princípios", 2 que balizam atualmente a implementação da sustentabilidade em nossas atividades. De forma evolutiva e pragmática, um segundo conjunto de princípios, de aplicação mais direta aos processos de produção, foi publicado para privilegiar a obtenção de rotas mais inovadoras e sustentáveis. ${ }^{3}$

Nesse cenário, atualmente existem oportunidades para o desenvolvimento industrial de tecnologias baseadas no emprego de matérias primas a partir de fontes renováveis, ${ }^{4}$ não focada apenas em biocombustíveis, mas buscando alternativas de exploração de biomassa, podendo oferecer rotas para a substituição e aproveitamento

*e-mail: mmvictor@ufba.br de produtos químicos. Cabe aqui salientar que o potencial de aproveitamento de fontes naturais, aliado às restrições ambientais de uso de produtos fósseis, permitirão desenvolver novas tecnologias visando a obtenção de produtos de interesse com alto valor agregado. Aliase a essa oportunidade que a disposição indevida e desnecessária de resíduos orgânicos é um problema crescente, devidos às emissões de gases de efeito estufa, especialmente metano, que decorrem da decomposição de material orgânico em aterros sanitários. ${ }^{5}$

Um excelente candidato para demonstrar este potencial de aproveitamento aos estudantes são os resíduos de frutas cítricas. Elas são as mais cultivadas no planeta, e também possuem maior dispersão geográfica de produção. ${ }^{6} \mathrm{O}$ Brasil é o maior produtor mundial de laranjas, responsável por mais de $50 \%$ da produção mundial de suco concentrado e também o maior exportador. Assim, a indústria cítrica nacional é um importante item do agronegócio brasileiro. ${ }^{7}$ Ademais, essa atividade industrial gera uma quantidade significativa de resíduos. Por exemplo, na safra 2018/2019, a produção de sucos de frutas cítricas, que consumiu 30\% da produção mundial de 100 milhões de toneladas, a quantidade de resíduos gerado foi calculado entre 50 a $70 \%$ do peso processado, resultando em uma quantidade de resíduos de biomassa, portanto com enorme potencial de aproveitamento para processamento e/ou extração de compostos bioativos.

O uso dos resíduos de cascas de cítricos sem diferenciação em seus constituintes individuais ainda é o principal modo de utilização, direcionado para uso na agricultura e como auxiliar em ração animal. Contudo, um uso mais racional dessa biomassa tem sido proposto, focando no seu emprego em biorrefinarias, produção de energia (etanol e biogás) e na extração de produtos de alto valor agregado e interesse comercial. ${ }^{8}$ Esses últimos produtos, que podem ser extraídos de resíduos de cascas de cítricos, têm particular utilização na indústria de cosméticos, de aditivos alimentares e na indústria farmacêutica. ${ }^{9}$

Dentre esses produtos, a hesperidina 1 (3',5,7-tri-hidróxi-4'-metóxi-flavanona-7-O-rutinosídeo, Figura 1) é o flavonoide característico e mais abundante presente nos tecidos das cascas da laranja comum [Citrus sinensis (L.) Osbeck]. A hesperidina é conhecida pelos benefícios associados ao seu consumo, pois exibe propriedades anti-inflamatória, ${ }^{10}$ anti-hipercolesterolêmica, ${ }^{11}$ diurética, ${ }^{12}$ neuroprotetiva, ${ }^{13}$ dentre outras. A naringina 2 


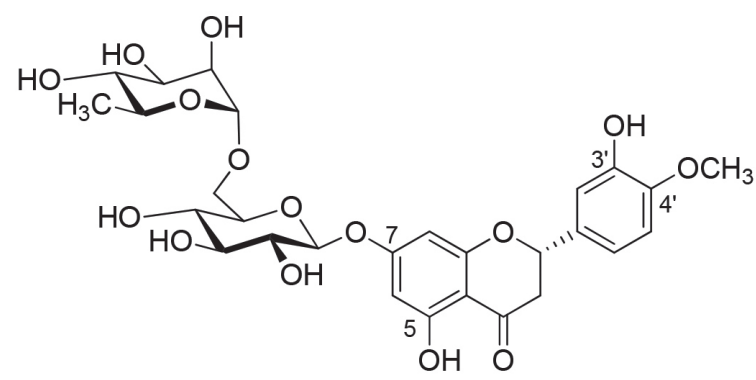

Hesperidina 1

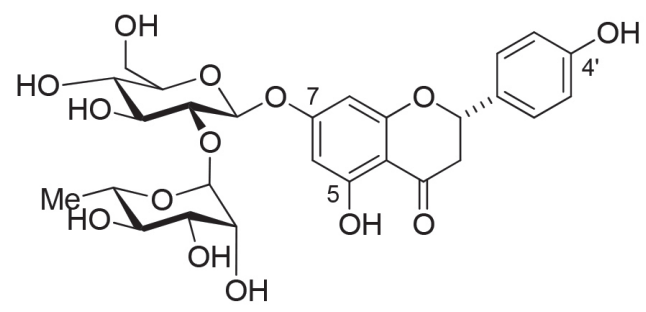

Naringina 2

Figura 1. Estruturas da hesperidina 1 e da naringina 2

(4',5,7-tri-hidróxi-flavanona-7-O-rhamnoglucosídeo) é o flavonoide que ocorre em maior concentração na grapefruit ou toranja (Citrus $x$. paradisi L.), um híbrido cítrico produzido pelo cruzamento entre o pomelo e a laranja comum. Essa flavona é responsável pelo sabor amargo da fruta e de seu suco, e também possui várias atividades biológicas comprovadas, tais como antioxidante, ${ }^{14}$ anticâncer, ${ }^{15}$ antiviral, ${ }^{16}$ anti-inflamatória, ${ }^{17}$ dentre outras.

Assim, devido à relevância do problema mundial de reaproveitamento de rejeitos orgânicos, uma visão crítica e aplicada com obtenção de insumos a partir de biomassa descartada pela indústria cítrica é altamente desejável para a formação de graduandos na área de química. Uma maneira de concretizar essa ação de formação profissional é realizar experimentos nas disciplinas práticas dos cursos de graduação que valorizem o uso de resíduos de biomassa, como forma a solidificar este conceito no discente. Levantamento da literatura indica que recentemente foram sugeridos experimentos em laboratórios de graduação empregando resíduos de milho (sabugo) para a obtenção de furfural, ${ }^{18}$ de cravo-da-índia para obtenção simultânea de eugenol e furfural, ${ }^{19}$ e de uso da glicerina obtida como subproduto na preparação do biodiesel para estudos de craqueamento térmico. ${ }^{20}$ Especialmente sobre o uso de resíduos de cítricos, já foram propostos experimentos para graduandos envolvendo extração e transformação de óleo essencial de casca de laranja, ${ }^{21}$ extração da pectina e seu uso na preparação de marmelada, ${ }^{22}$ e uso de casca de laranja, limão e bergamota como extratores de metais e corantes de águas residuais. ${ }^{23}$ Todavia, até o momento não existe descrito na literatura um experimento que use o resíduo das cascas de cítricos para obtenção de flavonoides na forma pura, especialmente hesperidina $\mathbf{1}$ e naringina $\mathbf{2}$, tal como descrito no presente trabalho.

\section{PARTE EXPERIMENTAL}

\section{Reagentes e equipamentos}

Metanol (MeOH) PA, etanol comercial $(\mathrm{EtOH}) 96^{\circ} \mathrm{GL}$ e diclorometano (DCM) PA foram usados de fontes comerciais sem purificação prévia. Os pontos de fusão foram obtidos em equipamento Microquímica MQAPF 301, com rampa de aquecimento de $2,5{ }^{\circ} \mathrm{C} \min ^{-1}$, através da técnica de lamínulas. Análises de cromatografia líquida de alta eficiência (CLAE/DAD) foram realizadas em equipamento Shimadzu, modelo Prominence, e com detecção em $270 \mathrm{~nm}$, empregando coluna C18 (Shim-pack PREP-ODS (H); $250.0 \times 4.6 \mathrm{~mm}$ ID, $5 \mu \mathrm{m}$, Shimadzu). O MeOH empregado na análise de CLAE foi de grau HPLC de marca Tedia e água Milli-q acidificada com ácido fórmico 0,2\% (Merck). O fluxo da fase móvel (MeOH:água acidificada 40:60) foi de $0,25 \mathrm{~mL} / \mathrm{min}$ e volume de injeção de $5 \mu \mathrm{L}$. O espectro na região do infravermelho foi feito em espectrofotômetro FTIR Perkin Elmer Spectrum 400 MID-NIR, empregando discos confeccionados com 3-5 mg de amostra e $100 \mathrm{mg}$ de $\mathrm{KBr}$.

OBS: devido à dificuldade de obtenção local, optamos por não realizar os espectros de $\mathrm{RMN}$ de ${ }^{1} \mathrm{H}$ e de ${ }^{13} \mathrm{C}$ dos flavonoides obtidos pelos alunos, mas sim fornecer de amostras já preparadas. Esses espectros estão disponíveis e são fornecidos no Material Suplementar (vide Figuras 1S-4S). Esses espectros foram registrados em equipamentos Bruker mod. Avance III $500 \mathrm{MHz}$ e Bruker mod. Avance III $400 \mathrm{MHz}$.

\section{Frutas}

As amostras de laranjas comuns [Citrus sinensis (L.) Osbeck] foram adquiridas em mercados locais e têm origem em produtores do estado da Bahia. As grapefruits (Citrus x paradisi L.) foram adquiridas em mercado local e são procedentes do Chile.

\section{Preparação das amostras}

As amostras de laranja comum e grapefruit foram finamente descascadas com facas para a remoção do flavedo (camada colorida externa) e, em seguida, o albedo (parte branca). Imediatamente após a parte branca (albedo) foi separada das membranas e vesículas (endocarpo ou polpa). Em seguida o albedo foi cortado em pequenos

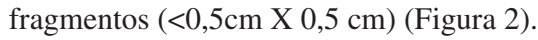

\section{Extração dos flavonoides}

Em um balão monotubulado de $500 \mathrm{~mL}$ foram adicionados cerca de $50 \mathrm{~g}$ de albedo picado e, em seguida, cerca de $200 \mathrm{~mL}$ do solvente extrator (ou o suficiente para cobrir o albedo). Um condensador de refluxo foi adaptado e o sistema foi submetido à extração por refluxo por 1 hora, utilizando-se manta de aquecimento. Após este tempo o refluxo foi interrompido, o solvente foi decantado e filtrado em papel de filtro por gravidade sem remover o albedo do balão, e um novo volume de solvente foi adicionado para uma segunda extração sob refluxo por mais 30 minutos. Ao final, o segundo volume de solvente foi decantado e adicionado à solução obtida na primeira extração. O solvente foi recuperado em sistema de destilação ou rotaevaporador, e $30 \mathrm{~mL}$ de água destilada foram adicionados à suspensão de sólidos obtida. Em seguida a suspensão foi transferida para frasco Erlenmeyer (um fluxograma simplificado pode ser encontrado no Material Suplementar).

Extração da hesperidina empregando laranja comum: a suspensão foi aquecida à $40-50^{\circ} \mathrm{C}$ por $10-15$ minutos em chapa de aquecimento e, em seguida, ainda quente, transferida para um funil de separação. Numa capela de exaustão, com agitação e cuidado, $5 \mathrm{~mL}$ de DCM foram adicionados. A mistura foi agitada vigorosamente em movimento circular, sem tampa, de forma que permanecesse um volume de DCM na fase inferior. Quando necessário, devido à perda de DCM por evaporação, volume adicional de $5 \mathrm{~mL}$ foi adicionado e a operação repetida. Em seguida, a fase orgânica inferior foi recolhida 


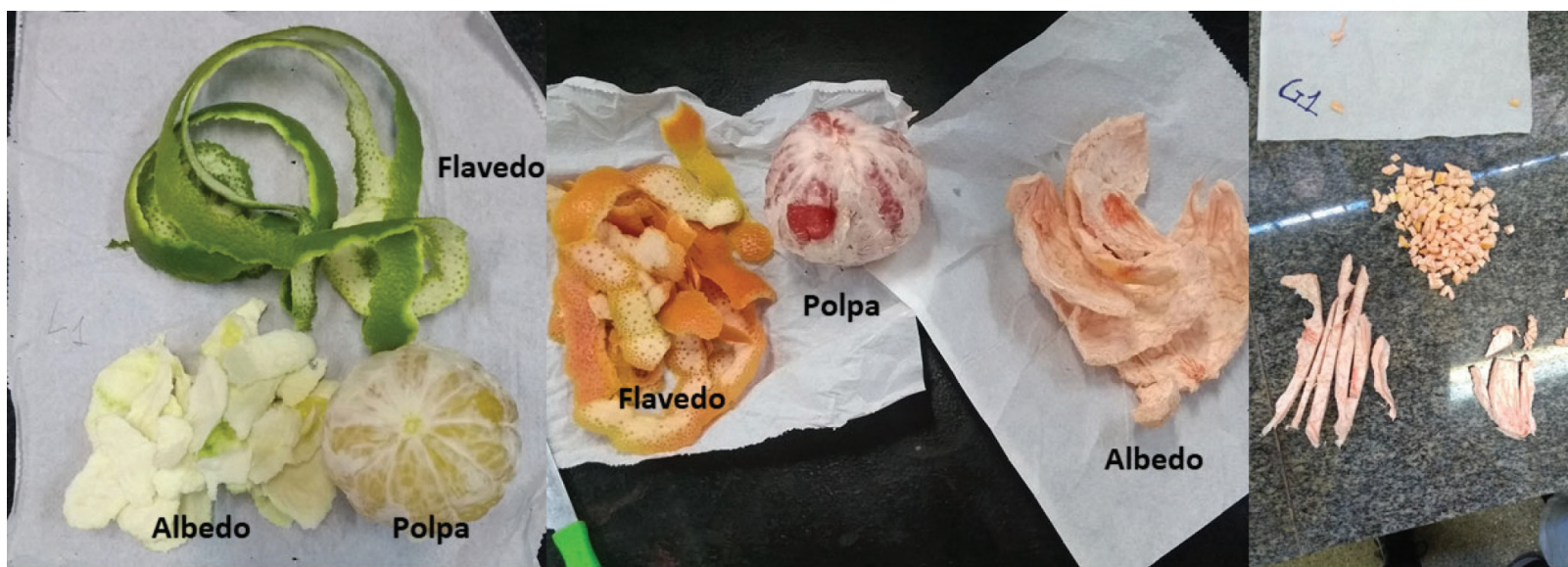

\section{Laranja comum}

Grapefruit

Corte do albedo

Figura 2. Separação dos cítricos laranja comum e grapefruit nos seus componentes albedo, flavedo e endocarpo/polpa (esquerda e centro); e preparação da amostra para extração (direita)

e os sólidos foram filtrados à vácuo em funil de Büchner com um papel previamente tarado. A secagem foi realizada em atmosfera em ambiente ausente de luminosidade.

Extração da naringina a partir de grapefruit: a suspensão obtida foi aquecida à $50-60^{\circ} \mathrm{C}$ por $10-15$ minutos ou até a completa dissolução dos sólidos. Sequencialmente, a solução foi transferida ainda quente para um funil de separação e, em capela de exaustão, $5 \mathrm{~mL}$ de DCM foram adicionados. A mistura foi agitada vigorosamente em movimento circular, sem tampa, com cuidado, de forma que permanecesse um volume de DCM na fase inferior do funil. Quando necessário, devido à perda de DCM por evaporação, volume adicional de $5 \mathrm{~mL}$ foi adicionado e a operação repetida. Em seguida o funil foi fechado, o conjunto identificado com etiqueta e o mesmo foi deixado em repouso para que, até a aula seguinte, houvesse formação de cristais (normalmente 3-4 dias). Após uma semana, a fase orgânica inferior foi removida e os sólidos filtrados à vácuo em funil de Büchner, empregando um papel de filtro previamente tarado. A secagem foi realizada em atmosfera em ambiente ausente de luminosidade.

Dados analíticos da hesperidina 1: sólido branco amorfo; IV $\left(\mathrm{KBr}, \mathrm{cm}^{-1}\right)$ : 3545, 3475, 2978, 2935, 2916, 1647, 1608, 1519, 1467, 1442, 1300, 1276, 1242, 1203, 1184, 1157, 1134, 1095, 1068, 1033; RMN de ${ }^{1} \mathrm{H}$ (DMSO-d $\left.\mathrm{D}_{6}, 400 \mathrm{MHz}\right): \delta$ (ppm) 12,02 (s, 1H, OH-5); 9,08 (sl., 1H, OH-3'); 6,94-6,89 ( $m, 3 \mathrm{H}, \mathrm{H}-2$ ', H-5'e H-6'); 6,14 (d, $J=6,4 \mathrm{~Hz}, 2 \mathrm{H}, \mathrm{H}-8$ e H-6); 5,50 ( $d d, J=12,2 ; 2,6 \mathrm{~Hz}, 1 \mathrm{H}, \mathrm{H}-2)$; 5,17 ( $t, J=5,5 \mathrm{~Hz}, 1 \mathrm{H}, \mathrm{H}-1$ '” '); 4,98 ( $d, J=7,3 \mathrm{~Hz}, 1 \mathrm{H}, \mathrm{H}-1$ '”); 4,67 $(d, J=4,9 \mathrm{~Hz}, 1 \mathrm{H}, \mathrm{H}-2$ "') $)$ 4,59 (d, J = 3,5 Hz, 1H, H-6"'); 4,53 ( $s$, 1H, H-1); 4.46 (d, $J=5,5 \mathrm{~Hz}, 1 \mathrm{H}, \mathrm{H}-4$ "' ); 4,05-4,14 (m, 1H, H-3"' e 6"); 3,82 (sl., 1H, H-4"); 3,78 (s, 3H, MeO-4'); 3,09-3,20 (m, 3H, $\mathrm{H}-3 \mathrm{a}) ; 2,78(d d, J=17,0 ; 2,6 \mathrm{~Hz}, 1 \mathrm{H}, \mathrm{H}-3 \mathrm{~b}) ; 1,09(d, J=6,1 \mathrm{~Hz}, 3 \mathrm{H}$, H-6"'); RMN de ${ }^{13} \mathrm{C}$ (DMSO- $\left.d_{6}, 125 \mathrm{MHz}\right): \delta$ (ppm) 197,0 (C-4); 165,2 (C-7); 163,2 (C-5); 162,5 (C-10); 148,0 (C-4'); 146,5 (C-3'); 130,9 (C-1'); 118,0 (C-6'); 114,2 (C-2'); 112,1 (C-5'); 103,3 (C-9); 100,6 (C-1"'); 99,5 (C-1”); 96,4 (C-6); 95,6 (C-8); 78,4 (C-2); 76,3 (C-5"); 75,6(C-3"'); 73,0 (C-4"”); 72,1 (C-2”); 70,7 (C-4"); 70,3 (C-3"'); 69,6 (C-2"''); 68,3 (C-5'”); 66,1 (C-6”); 55,7 (MeO-4'); 42,1 (C-3); 17,9 (C-6"').

Dados analíticos da naringina 2: sólido branco cristalino; IV $\left(\mathrm{KBr}, \mathrm{cm}^{-1}\right) 3372,1645,1632,1583,1177,1038$ e $820 ; \mathrm{RMN}$ de ${ }^{1} \mathrm{H}$ $\left(\mathrm{CD}_{3} \mathrm{OD}, 400 \mathrm{MHz}\right): \delta$ (ppm) 7,32 (d, $J=8,5 \mathrm{~Hz}, 2 \mathrm{H}, \mathrm{H}-2^{\prime}$; H-6'); 6,83 (d, $J=8,5 \mathrm{~Hz}, 2 \mathrm{H}, \mathrm{H}_{-3}$ '; H-5'); 6,19 (d, $J=2,1 \mathrm{~Hz}, 1 \mathrm{H}, \mathrm{H}-6$ ); 6,16 (d, $J=2,1 \mathrm{~Hz}, 1 \mathrm{H}, \mathrm{H}-8) ; 5,40-5,36$ (m, 1H, H-2); 5, 25-5, 24 (m, 1H, H-1 '”); 5,13-5,11 (m, 1H, H-1"); 3,94-3,36 (m, 10H, H-6", H-5"', H-5", H-3"', H-3", H-2", H-2", H-4"', H-4"); 3, 17-3, 15 (m, 1H, H- $\left.3_{\text {ax }}\right) ; 2,76$ (dd, $\left.J=17,2 ; 2,8 \mathrm{~Hz}, 1 \mathrm{H}, \mathrm{H}-3_{\mathrm{eq}}\right) ; 1,29$ (d, $J=6,2 \mathrm{~Hz}, 1 \mathrm{H}$, H-6"'); RMN de ${ }^{13} \mathrm{C}$ (CD $\left.\mathrm{CD}_{3} \mathrm{OD}, 125 \mathrm{MHz}\right): \delta$ (ppm) 197,2 (C-4); 165,2 (C-7); 163,6 (C-5); 103,5 (C-10); 157,7 (C-4'); 115,0 (C-3'); 129,5 (C-1'); 127,8 (C-6'); 127,8 (C-2'); 115,0 (C-5'); 163,2 (C-9); 101,1 (C-2”); 98,0 (C-2"”); 96,5 (C-6); 95,4 (C-8); 79,3 (C-2); 77,8 (C-4"); 77,5 (C-6"); 76,7 (C-3"); 72,5 (C-5"'); 70,8 (C-3"' e C-4"'), 69,8 (C-5"); 68,6 (C-6"'); 60,9 (CH $-\mathrm{C6} ")$; 42,5 (C-3); 16,9 (CH $-\mathrm{C6}$ "').

\section{RESULTADOS E DISCUSSÃO}

O desenvolvimento de novas metodologias de extração da naringina a partir do resíduo de cascas de grapefruit e da hesperidina a partir da laranja comum foram alvo de investigação recente..$^{24,25}$ Ambas decorreram de aprimoramento de técnicas descritas na literatura, e foram baseadas no interesse de obtenção dos flavonoides como compostos de partida para a preparação de outras substâncias com atividades biológicas. Em função do sucesso das metodologias adotadas e da facilidade de realização dos procedimentos experimentais descritos nesses trabalhos, uma adaptação para discentes de graduação foi realizada. Além disso, essa proposta inclui também discussão da temática envolvida na utilização de resíduos de biomassa gerados pela indústria para a obtenção de produtos mais complexos de interesse científico e tecnológico.

O público alvo foram estudantes no último ano do curso de bacharelado em Química, que cursaram a disciplina QUI-A64 (Química Orgânica Experimental III, 06 créditos), última disciplina experimental do curso de Química Orgânica. Como a disciplina se desenrola sem interrupção (uma tarde completa, das 13:00h até às 18:30h), foi possível realizar os dois experimentos em 3 encontros completos. No caso de adaptação a uma disciplina de menor creditação, algumas etapas precisariam ser suprimidas, com consequente diminuição do rendimento da extração, mas mesmo assim poderá ser realizada sem comprometimento do resultado final. Além disso, o número de encontros dependerá da participação ou não dos alunos durante as etapas analíticas de caracterização (cromatografia líquida e espectrometria no infravermelho). No nosso caso, como faziam parte da proposta de formação, um encontro adicional foi necessário. Somente para as etapas do laboratório dois encontros são suficientes.

O experimento inicia com o tratamento das amostras. No caso da laranja comum, de custo baixo e de ampla disponibilidade, os alunos, 
organizados em duplas, normalmente proveram as amostras. Para cada dupla cerca de 4-5 laranjas foram suficientes. No entanto, se necessário, restos de cantinas que preparam sucos também podem ser utilizados, eliminando o custo de aquisição. No caso da grapefruit, a disponibilidade não é ampla. Em Salvador, poucos estabelecimentos oferecem essa fruta e com custo relativamente mais elevado. Nesse caso, normalmente a instituição deve arcar com as despesas, e cerca de 2-3 frutas grandes foram suficientes para cada dupla.

As frutas foram pesadas em balança e, com o auxílio de uma faca, seus componentes foram separados (vide Figura 2). Em seguida, os componentes foram pesados individualmente, como forma a determinar a composição em peso de cada parte. As laranjas pesaram em média entre 150 e $200 \mathrm{~g}$, as massas dos flavedos oscilaram entre 19 e $30 \mathrm{~g}$ (média 13,5\% p/p) e os endocarpos (polpa) entre 120 e $185 \mathrm{~g}$ $(85,0 \% \mathrm{p} / \mathrm{p})$. A parte branca esponjosa, o albedo, fonte de maior concentração de flavonoides, foi obtido na faixa entre 10 e $23 \mathrm{~g}$ por fruta, sendo responsável em média por $16,5 \%$ do peso. No caso da grapefruit, as frutas apresentaram massas maiores (entre 250 e $320 \mathrm{~g}$ ), e flavedo (entre 44 e $50 \mathrm{~g}$ ) e endocarpo (entre 175 e $220 \mathrm{~g}$ ) representaram $15,5 \%$ e $67,0 \%$ p/p, respectivamente. $O$ albedo oscilou entre 31 e $69 \mathrm{~g}$ por fruta $(17,5 \% \mathrm{p} / \mathrm{p})$. Obviamente, em se tratando de frutas, muita variação poderá ser encontrada por região e época do ano, mas esses valores podem ser considerados referências. Tomando-se os cuidados de limpeza prévia da balança e de proteção dos componentes das bancadas com papéis ou plásticos limpos, e respeitando as normas de segurança, o flavedo foi descartado e as polpas foram consumidas (fora do laboratório). $\mathrm{O}$ albedo foi cortado em pequenos fragmentos (inicialmente tiras, depois de forma transversal, Figura 2) e as amostras de cada fruta cítrica (laranja comum e grapefruit, separadamente) foram misturadas, para homogeneização das amostras.

Em seguida, iniciou-se a extração que, em trabalhos anteriores, foi realizada com metanol. No entanto, para minimizar os riscos de intoxicação e diminuição de custos, as extrações também foram realizadas com etanol comercial comum ( $\left.96^{\circ} \mathrm{GL}\right)$. Desse modo, extrações tanto com $\mathrm{MeOH}$ como com EtOH de ambos albedos puderam ser comparadas. Esses dois álcoois foram considerados apenas como "solventes", sendo que nos resultados finais foram relatados separadamente. As duas extrações sob refluxo foram realizadas em sequência, com solvente suficiente para manter as amostras de albedo imersas. Para a primeira remoção de solvente, uma decantação cuidadosa foi realizada, e permitiu sem dificuldades que todo o albedo permanecesse no balão para ser submetida a uma segunda extração. Em caso de disciplinas com apenas 4 períodos, uma única extração de 1 hora poderia ser realizada. Após a remoção do solvente, que no nosso caso foi realizada tanto em evaporador rotatório quanto em sistemas de destilação, obteve-se um resíduo (uma suspensão) contendo os extratos brutos da hesperidina (no caso de extração do albedo da laranja comum) e da naringina (grapefruit).

Os procedimentos de isolamento em cada caso foram distintos, devido à diferença de solubilidade em água entre a hesperidina 1 e a naringina 2. Para a hesperidina $\mathbf{1}$, que possui baixa solubilidade em

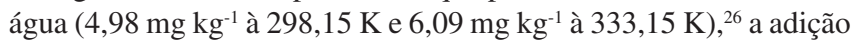
de água e leve aquecimento não promove a solubilização dos sólidos. Logo, a suspensão formada foi extraída com diclorometano. Segundo a literatura, essa extração com solvente clorado deve ser efetuada para remoção dos flavonoides metoxilados comuns nas cascas das frutas, ${ }^{27}$ menos solúveis em água, e pode ser considerada como uma etapa de pré-purificação, ainda que efetuada sobre a suspensão da hesperidina 1. Com o sólido já presente, a fase orgânica inferior foi removida $^{28}$ e a suspensão filtrada à vácuo em funil de Büchner com um papel de filtro previamente cortado e tarado. Assim, a extração efetuada propiciou a obtenção do flavonoide de forma bruta ao final da primeira aula, praticidade que precisa ser considerada no experimento de escolha. O sólido amorfo foi obtido com uma coloração do creme até um marrom claro (Figura 3 ).

No caso do tratamento de purificação da extração do albedo da grapefruit, que forneceu a naringina $\mathbf{2}$, o procedimento foi efetuado de modo diferente. A solubilidade de $2 \mathrm{em}$ água $\left(0,50 \mathrm{~g} \mathrm{~kg}^{-1}\right.$ à $20^{\circ} \mathrm{C}$ e $42,21 \mathrm{~g} \mathrm{~kg}^{-1}$ à $\left.65^{\circ} \mathrm{C}\right)^{29}$ faz com que, durante o aquecimento com água, a solução se apresentasse homogênea. Nesse caso, após o aquecimento com água e extração com diclorometano, obteve-se o flavonoide da solução aquosa apenas após um período de cristalização, que no nosso caso foi de 1 semana (intervalo entre encontros). Por outro lado, o produto foi obtido na forma cristalina, após a execução dos procedimentos necessários para a filtração à vácuo (Figura 4).

Para fins de cálculos de rendimento dos flavonoides obtidos, tomaram-se como padrão as medidas adotadas na literatura, que consideram como referência a massa de albedo seco utilizada na
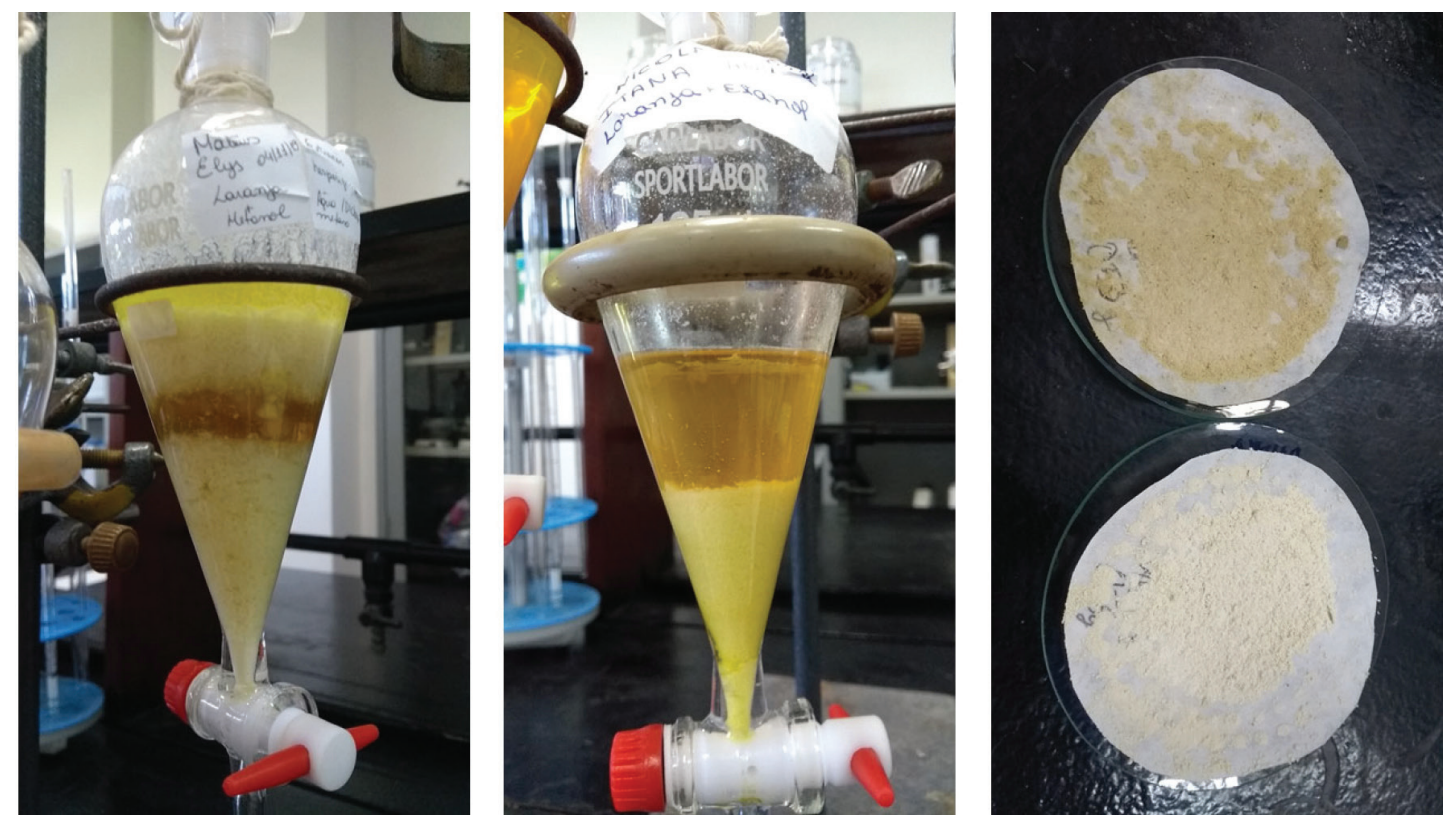

Figura 3. Aspecto dos funis de separação na extração com diclorometano da suspensão de hesperidina 1 (esquerda e centro) e dos sólidos depois de filtrados (direita) 

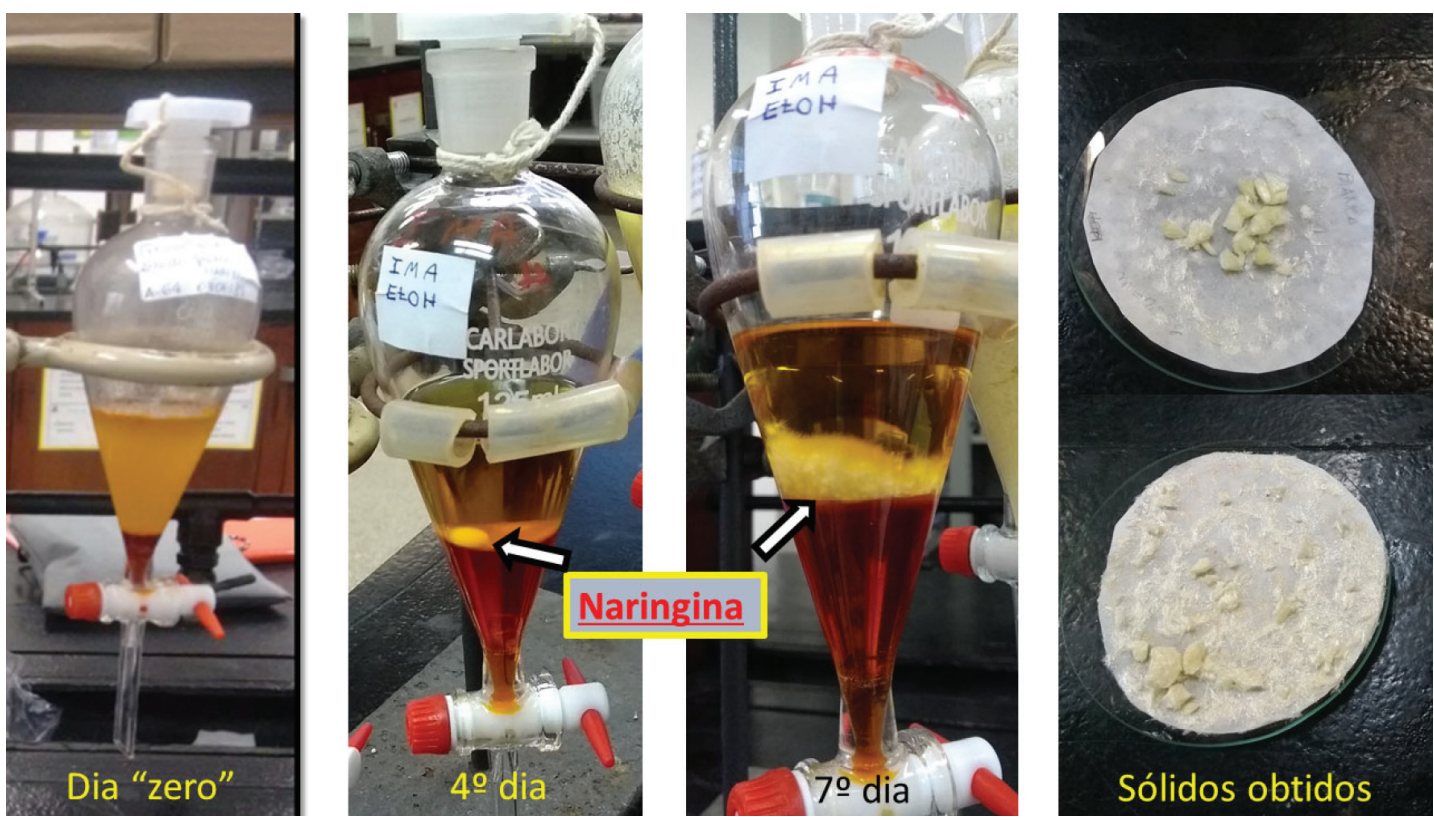

Figura 4. Evolução do aparecimento da naringina 2 na extração do albedo do grapefruit (esq. para dir.): dia do tratamento, com 4 dias e com 7 dias. Na imagem da direita os sólidos cristalinos obtidos

extração. Como no presente experimento foram empregados albedos frescos (úmidos), tomaram-se os valores de relação entre albedo seco e úmido aqueles descritos na literatura, ou seja, de $33,1 \% \mathrm{~m} / \mathrm{m}$ para a laranja comum ${ }^{25}$ e $24,4 \% \mathrm{~m} / \mathrm{m}$ para a grapefruit. $^{24}$

Alguns dos dados obtidos pelos discentes nos experimentos realizados no laboratório encontram-se descritos na Tabela 1. De um modo geral, a extração da hesperidina $\mathbf{1}$ a partir da casca de laranja mostrou-se mais eficiente quando metanol foi empregado como solvente extrator, enquanto que no caso da naringina 2 , extraída a partir do albedo da casca da grapefruit, o emprego de etanol forneceu melhores rendimentos.

Após isolamento e purificação dos flavonoides, os sólidos obtidos tiveram seus pontos de fusão determinados e comparados com dados disponíveis na literatura. ${ }^{30}$ No caso das extrações fornecendo hesperidina, independente do solvente empregado, os valores ficaram bastante próximos, inclusive com os dados da literatura que também não são muito discrepantes. Contudo, para a naringina, quando o solvente empregado na extração foi o metanol, o valor do PF se apresentou abaixo dos valores obtidos quando o solvente extrator foi o etanol comercial. Contudo, em consulta à base de dados, pode ser verificado que a naringina possui valores diferentes de pontos de fusão relatados, em faixas bem distintas uma da outra. Assim, essa variabilidade poderá ser observada, uma vez que análises posteriores mostraram que ambos sólidos tinham a mesma pureza. ${ }^{31}$

Além da medida do ponto de fusão, um teste rápido realizado no laboratório foi o teste de identificação de fenóis, que utiliza uma solução de cloreto férrico. ${ }^{32}$ Para esse teste, uma mistura de água e etanol deve ser empregada devido à baixa solubilidade dos flavonoides em água à temperatura ambiente. Uma cor laranja pouco intensa é obtida após algum tempo de espera. Outros testes rápidos também podem ser realizados, se desejado. ${ }^{33}$

Para a realização das análises no infravermelho, as amostras precisam estar bem secas. No caso da hesperidina 1, que normalmente é obtida no primeiro encontro e o material isolado foi mantido à secagem por uma semana, esse detalhe não representa nenhum problema. No caso da naringina 2 , que é filtrada somente no segundo encontro, a amostra isolada deve ser submetida à secagem em estufa $\left(60-80{ }^{\circ} \mathrm{C}\right)$ durante aproximadamente 30 minutos, período suficiente para garantir a total retirada da água. Com a correta preparação das amostras, as análises foram realizadas na forma de solução sólida em $\mathrm{KBr}$ (2-3 mg de amostra para $100 \mathrm{mg}$ de $\mathrm{KBr}$ ). Os discos preparados foram então analisados, e permitiram a obtenção dos espectros que mostraram as

Tabela 1. Dados experimentais da extração dos flavonoides hesperidina 1 e naringina 2

\begin{tabular}{|c|c|c|c|c|c|}
\hline \multicolumn{6}{|c|}{ Hesperidina } \\
\hline Solvente extrator & Albedo fresco & Albedo seco (calculado) & Hesperidina & Rendimento & $\mathrm{PF}\left({ }^{\circ} \mathrm{C}\right)^{\mathrm{a}}$ \\
\hline $\mathrm{MeOH}$ & $50,05 \mathrm{~g}$ & $16,57 \mathrm{~g}$ & $0,46 \mathrm{~g}$ & $2,8 \%$ & $234-238$ \\
\hline $\mathrm{MeOH}$ & $50,02 \mathrm{~g}$ & $16,56 \mathrm{~g}$ & $0,64 \mathrm{~g}$ & $3,9 \%$ & $243-244$ \\
\hline EtOH & $50,09 \mathrm{~g}$ & $15,58 \mathrm{~g}$ & $0,41 \mathrm{~g}$ & $2,5 \%$ & $244-247$ \\
\hline $\mathrm{EtOH}$ & $50,01 \mathrm{~g}$ & $16,55 \mathrm{~g}$ & $0,43 \mathrm{~g}$ & $2,6 \%$ & $241-243$ \\
\hline \multicolumn{6}{|c|}{ Naringina } \\
\hline Solvente extrator & Albedo fresco & Albedo seco (calculado) & Naringina & Rendimento & $\operatorname{PF}\left({ }^{\circ} \mathrm{C}\right)^{\mathrm{b}}$ \\
\hline $\mathrm{MeOH}$ & $50,10 \mathrm{~g}$ & $12,22 \mathrm{~g}$ & $0,44 \mathrm{~g}$ & $3,6 \%$ & $82-85$ \\
\hline $\mathrm{EtOH}$ & $50,02 \mathrm{~g}$ & $12,20 \mathrm{~g}$ & $0,67 \mathrm{~g}$ & $5,5 \%$ & $169-171$ \\
\hline $\mathrm{EtOH}$ & $61,19 \mathrm{~g}$ & $14,93 \mathrm{~g}$ & $0,85 \mathrm{~g}$ & $5,7 \%$ & $171-174$ \\
\hline
\end{tabular}

a) dados de PF na literatura: $262{ }^{\circ} \mathrm{C}, 250-255^{\circ} \mathrm{C}, 258-262{ }^{\circ} \mathrm{C}, 250-255^{\circ} \mathrm{C}$ (decomp.); b) dados de $\mathrm{PF}$ da literatura: $83^{\circ} \mathrm{C}, 166^{\circ} \mathrm{C}, 171^{\circ} \mathrm{C}$. 

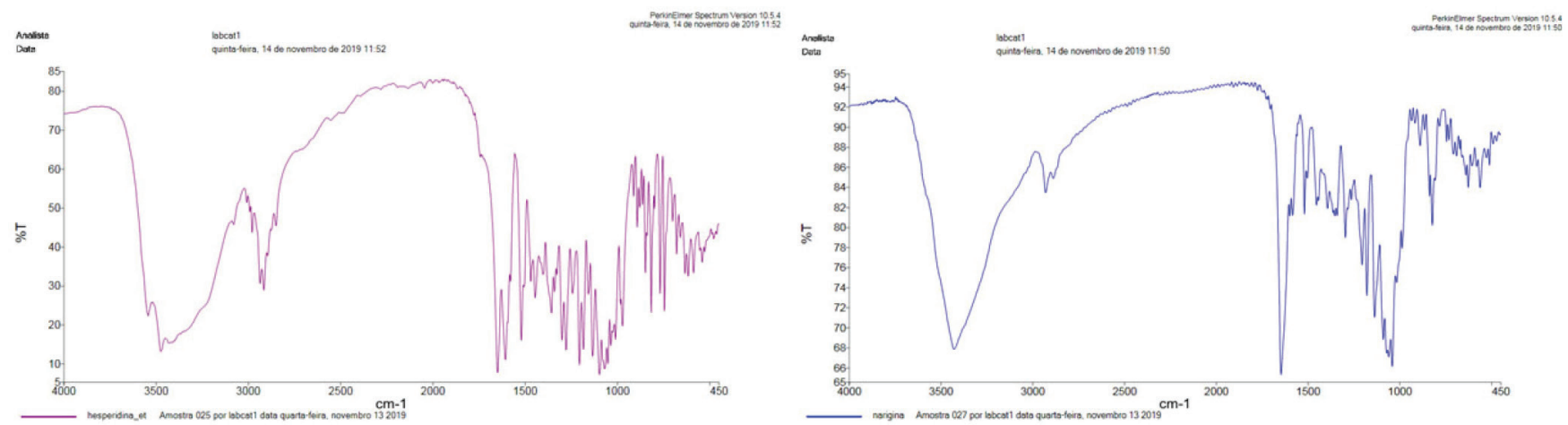

Figura 5. Espectros no infravermelho (discos de KBr) da hesperidina 1 (esquerda) e naringina 2 (direita)

bandas principais esperadas para as estruturas (Figura 5): ${ }^{34}$ bandas de hidroxilas (estiramento da ligação O-H) na região entre 3600 e 3300 $\mathrm{cm}^{-1}$, inclusive com a presença de hidroxilas com bandas finas (ligações de hidrogênio), mais visíveis na hesperidina; forte banda de estiramento $\mathrm{C}=\mathrm{O}$ de carbonila conjugada ao redor de $1650 \mathrm{~cm}^{-1}$; e os estiramentos das ligações C-O na região entre 1000 e $1200 \mathrm{~cm}^{-1}$. Deformações das ligações C-H referentes a anéis aromáticos também são visíveis, mas devido à complexidade são de interpretação um pouco mais difícil.

Finalmente, as amostras dos flavonoides isolados e purificados pelos discentes foram analisadas por cromatografia líquida de alta eficiência (CLAE/DAD), como uma forma mais apurada de determinação da pureza dos produtos naturais obtidos, registro dos espectros de UV e de validação da metodologia empregada. Os alunos foram então levados a um laboratório de pesquisa em produtos naturais, que possui um equipamento de CLAE em operação e que já analisou os compostos isolados (Tabela 2). Os discentes realizaram a preparação das soluções, que envolvem pesagem de pequenas quantidades das amostras isoladas (cerca de $5 \mathrm{mg}$ em balão volumétrico de $5 \mathrm{~mL}$, concentração final de $\sim 1 \mathrm{mg} \mathrm{mL}^{-1}$ ), e a soluções foram filtradas (cerca de $1 \mathrm{~mL}$ ) para um frasco vial e então analisadas (para cromatogramas e espectros de UV vide Material Suplementar). Observando os resultados de pureza obtidos, pode-se verificar que, no caso da extração da hesperidina 1 a partir do albedo da casca da laranja comum, o cromatograma apresenta uma leve tendência de melhor pureza do flavonoide obtido no procedimento de extração com $\mathrm{MeOH}$ como solvente extrator. Já no caso da extração da naringina $\mathbf{2}$, não parece haver diferença considerável entre a pureza do flavonoide extraído a partir da grapefruit com $\mathrm{MeOH}$ ou EtOH. É digno de nota que CCD não pode ser empregada como método para determinação da pureza do flavonoide uma vez que hesperidina é totalmente insolúvel em solventes orgânicos comuns utilizados em laboratórios didáticos. Em laboratórios com infraestrutura mais completa e acessível, espectros de RMN e espectrometria de massas com ionização eletrospray ou ionização química à pressão atmosférica podem ser utilizados na identificação e determinação da pureza dos produtos.

Tabela 2. Pureza (área \%) dos flavonoides hesperidina $\mathbf{1}$ e naringina 2 analisados por CLAE

\begin{tabular}{cccc}
\hline \multicolumn{2}{c}{ Hesperidina $^{\mathrm{a}}$} & \multicolumn{2}{c}{ Naringina $^{\mathrm{b}}$} \\
\hline Solvente extrator & Área \% & Solvente extrator & Área \% \\
\hline $\mathrm{MeOH}$ & 89,20 & $\mathrm{MeOH}$ & 94,92 \\
$\mathrm{MeOH}$ & 90,16 & $\mathrm{EtOH}$ & 96,12 \\
$\mathrm{EtOH}$ & 83,45 & $\mathrm{EtOH}$ & 90,31 \\
EtOH & 89,63 & & \\
\hline
\end{tabular}

a) Os tempos de retenção variaram entre os semestres entre 19,7 e 21,0 minutos. b) Os tempos de retenção variaram entre os semestres entre 19,2 e 20,5 minutos.

\section{CONSIDERAÇÕES FINAIS}

O presente artigo demonstrou que o uso de resíduos de cascas de frutas cítricas, laranja comum e grapefruit, são perfeitamente viáveis para a efetiva extração e isolamento dos flavonoides hesperidina e naringina, respectivamente, em um experimento dedicado ao curso de graduação em Química. Os rendimentos obtidos foram entre 2,5 e $3,9 \% \mathrm{~m} / \mathrm{m}$ de albedo seco de laranja comum para a hesperidina $\mathbf{1}$, e entre 3,6 e $5,7 \% \mathrm{~m} / \mathrm{m}$ de albedo seco da grapefruit para a naringina 2. A prática requer no mínimo dois encontros, e utiliza materiais e reagentes disponíveis nos laboratórios de ensino. Também foi demonstrado que a extração pode ser realizada com álcool etílico comum, o que torna o experimento mais seguro, menos tóxico e mais econômico, não trazendo nenhum comprometimento considerável ao rendimento ou pureza dos flavonoides isolados. Também as boas quantidades obtidas dos flavonoides (entre 0,40 e 0,60 g) fazem esse prazeroso experimento de fácil realização, mesmo aos laboratórios de ensino que só possuam vidrarias e equipamentos ordinários. Desse modo, o uso de resíduos comuns e facilmente acessíveis das frutas cítricas permitiu levar aos estudantes à compreensão de valorização de utilização da biomassa, da extração de produtos com valor e das várias oportunidades que podem advir desta ação sustentável da Química.

\section{MATERIAL SUPLEMENTAR}

Mais detalhes experimentais, dados da extração e espectros IV das amostras de hesperidina (1) e naringina (2) podem ser obtidos em http://quimicanova.sbq.org.br, em formato pdf, com livre acesso.

\section{AGRADECIMENTOS}

Os autores agradecem ao CNPq e ao INCT E\&A pelo suporte financeiro, à CAPES pelas bolsas e ao IQ-UFBA pelo suporte institucional. O LabMulti (CIENAM/UFBA) e a Dr ${ }^{\mathrm{a}}$ Fernanda T. Cruz precisam ser agradecidos pelos espectros no infravermelho. Os autores agradecem aos alunos da disciplina QUI-A64, Química Orgânica Experimental III, dos semestres 2019/1 e 2019/2, pelo entusiasmo e comprometimento na execução deste projeto experimental.

\section{REFERÊNCIAS E NOTAS}

1. Farias, L. A.; Fávaro, D. I. T.; Quim. Nova 2011, 34, 1089.

2. Anastas, P. T.; Warner, J.; Green Chemistry: Theory and Practice; Oxford University Press: Oxford, 1998.

3. Winterton, N.; Green Chem. 2001, 3, G73.

4. Coutinho, P.; Bomtempo, J. V.; Quim. Nova 2011, 34, 910.

5. Themelis, N. J.; Ulloa, P. A.; Renewable Energy 2007, 32, 1243.

6. Balu, A. M.; Budarin, V.; Shuttleworth, P. S.; Pfaltzgraff, L. A.; Waldron, K.; Luque, R.; Clark, J. H.; ChemSusChem 2012, 5, 1694. 
7. US Department of Agriculture, Citrus: World Markets and Trade, Report July 2019.

8. Zema, D. A.; Calabrò, P. S.; Folino, A.; Tamburino, V.; Zappia, G.; Zimbone, S. M.; Waste Manage. 2018, 80, 252.

9. Sharma, K.; Mahato, N.; Lee, Y. R.; Rev. Chem. Eng. 2018, 1.

10. Galati, E. M.; Monforte, M. T.; Kirjavainen, S.; Forestieri, A. M.; Trovato, A.; Tripodo, M. M.; Farmaco 1994, 40, 709.

11. Bok, S. H.; Lee, S. H.; Park, Y. B.; Bae, K. H.; Son, K. H.; Jeong, T. S.; Choi, M. S.; J. Nutr. 1999, 129, 1182.

12. Galati, E. M.; Kirjavainen, S.; Forestieri, A. M.; Rossitto, A.; Monforte, M. T.; Farmaco 1996, 51, 219.

13. Raza, S. S.; Khan, M. M.; Ahmad, A.; Ashafaq, M.; Khuwaja, G.; Tabassum, R.; Javed, H.; Siddiqui, M. S.; Safhi, M. M.; Islam, F.; Brain Res. 2011, 1420, 93.

14. Burda, S.; Oleszek, W.; J. Agric. Food Chem. 2001, 49, 2774.

15. Kim, D. I.; Lee, S. J.; Lee, S. B.; Park, K.; Kim, W. J.; Moon, S. K.; Carcinogenesis 2008, 29, 1701.

16. Nafisi, S.; Hashemi, M.; Rajabi, M.; Tajmir-Riahi, H. A.; DNA Cell Biol. 2008, 27, 433 .

17. Ribeiro, I. A.; Rocha, J.; Sepodes, B.; Mota-Filipe, H.; Ribeiro, M. H.; J. Mol. Catal. B: Enzym. 2008, 52-53, 13.

18. Ribeiro, P. R.; Carvalho, J. R. M.; Geris, R.; Queiroz, V.; Fascio, M.; Quim. Nova 2012, 35, 1046.

19. Cunha, S.; Lustosa, D. M.; Conceição, N. D.; Fascio, M.; Magalhães,V.; Quim. Nova 2012, 35, 638

20. Riatto, V. B.; Victor, M. M.; Cunha, S.; Magalhães, A. C. R.; Cruz, F. T.; Carriço, C. S.; Quim. Nova 2015, 38, 727.

21. Baptistella, L. H. B.; Imamura, P. M.; Melo, L. V.; Castello, C.; Quim. Nova 2009, 32, 1069.

22. Mackenzie, L. S.; Tyrrell, H.; Thomas, R.; Matharu, A. S.; Clark, J. H.; Hurst, G. A.; J. Chem. Educ. 2019, 96, 3025.

23. Samet, C.; Valiyaveettil, S.; J. Chem. Educ. 2018, 95, 1354.

24. Victor, M. M.; David, J. M.; Sakukuma, M. C. K.; França, E. L.; Nunes, A. V. J.; Green Process. Synth. 2018, 7, 524.
25. Victor, M. M.; David, J. M.; Cortez, M. V. M.; Leite, J. L.; Silva, G. S. B.; Waste Biomass Valori. (2020), doi.org/10.1007/s12649-020-00982-x.

26. Anwer, M. K.; Al-Shdefat, R.; Jamil, S.; Alam, P.; Abdel-Kader, M. S.; Shakeel, F.; J. Chem. Eng. Data 2014, 59, 2065.

27. Sudto, K.; Pornpakakul, S.; Wanichwecharungruang, S.; Int. J. Food Sci. Technol. 2009, 44, 1737.

28. Em alguns casos o sólido formado não permitiu a completa visualização da fase orgânica clorada inferior. Mesmo assim, a suspensão foi filtrada sem problemas para o isolamento da hesperidina bruta.

29. Pulley, G. N.; Ind. Eng. Chem. Anal. Ed. 1936, 8, 360.

30. https://pubchem.ncbi.nlm.nih.gov, acessadas em julho 2020; http://www. chemspider.com; http://scifinder.cas.org, acessada em julho 2020.

31. Apesar de não ser o foco do experimento e não termos feito nenhuma análise que comprove tal suposição, é possível que estejamos diante de um caso de polimorfismo, já que os solventes de origem são diferentes e os bancos de dados informados remetem a dois valores distintos de pontos de fusão para a naringina. Para exemplo, ver Araújo, G. L. B.; Pitalunga Jr, A.; Antonio, S. G.; Santos, C. O. P.; Matos, J. R.; Rev. Cienc. Farm. Básica Apl. 2012, 33, 27.

32. Shriner, R. L.; Fuson, R. C.; Curtin, D. Y.; Morril, T. C.; The Systematic Identification of Organic Compounds, $6^{\mathrm{a}}$ ed., John Wiley \& Sons, New York, 1980

33. Para análise de cromatografia em camada delgada (CCD - plaquinha), a naringina $(5-10 \mathrm{mg})$ pode ser dissolvida em $1 \mathrm{~mL}$ de mistura de acetato de etila:metanol (1:1) e eluída na mesma solução com rf $\sim 0,5$. As soluções reveladoras podem ser solução de $\mathrm{KMnO}_{4}$ (mancha marrom) ou vanilina (mancha marrom escura). Já análise da hesperidina através desta técnica é muito difícil e não recomendada, visto ser essencialmente insolúvel nos solventes ordinários de laboratórios: Anwer, K. K.; AlShdefat, R.; Jamil, S.; Alam, P.; Abdel-Kader, M. S.; Shakeel, F.; J. Chem. Eng. Data 2014, 59, 2065.

34. Lopes, W. A.; Fascio, M.; Quim. Nova 2004, 27, 670. 